\title{
Is Practical Reasoning Presumptive?
}

\section{Christian Kock University of Copenhagen}

\begin{abstract}
Douglas Walton has done extensive and valuable work on the concepts of presumption and practical reasoning. However, Walton's attempt to model practical reasoning as presumptive is misguided. The notions of "inference" and of the burden of proof shifting back and forth between proponent and respondent are misleading and lead to counterintuitive consequences. Because the issue in practical reasoning is a proposal, not a proposition, there are, in the standard case, several perfectly good reasons on both sides simultaneously, which implies that argument appraisal necessarily contains a subjective element-a fact argumentation theory needs to conceptualize.
\end{abstract}

\begin{abstract}
Résumé: Douglas Walton a fait un travail considérable et précieux sur les concepts de présomption et de raisonnement pratique. Toutefois, ses tentatives de baser le raisonnement pratique sur le raisonnement présomptif sont peu judicieuses. Les notions d'inférence et de charge de preuve échangée entre un partisan et un adversaire sont trompeuses et mènent à des conséquences contreintuitives. Puisqu'un raisonnement pratique concentre sur une offre et non sur une proposition, il y a dans les cas typiques diverses raisons parfaitement acceptables qui appuient les positions opposées, ce qui implique que l'évaluation d'un argument contient nécessairement un élément subjectif-un fait que la théorie d'argumentation a besoin de conceptualiser.
\end{abstract}

Keywords: practical reasoning, presumption, presumptive reasoning, Douglas Walton, inference, burden of proof, proposal, proposition, Euro debate, argument appraisal, objetivity, subjectivity, Robert Pinto, Trudy Govier, Carl Wellman, relativism

\section{Introduction}

One of many notions in argumentation theory that have received deserved recognition thanks to the work of Douglas Walton is presumptive reasoning. Several items on his impressive list of publications deal with it (among them 1991, 1993, 1996a, 1997a, 2001). It means, as is well known, a type of argumentation midway between assertion and assumption: in its basic form, a proponent offers an argument for a claim, and this argument is seen as sufficient to shift the burden of proof to those who want to question the claim: "With presumption then, the burden of (dis)proof lies on the respondent, not on the proponent" (Walton 1996, xii). The opponent/ respondent must either (presumptively) accept the claim or rebut the argument. Presumptive reasoning, thus conceived, creates a special kind of inference, different from both deductive and inductive inference, and characterized in particular by the shifting of the burden of proof. It is "nonmonotonic" and can be modeled with the 
calculus for "plausible reasoning" suggested by Rescher (1976). Other related concepts are "default reasoning" (as in Reiter 1980) and "defeasibility." Walton has shown that presumptive reasoning is widespread in real-life argumentation of any kind.

Beside the burden-of-proof criterion, the other crucial component of Walton's theory of presumptive reasoning is the notion of argumentation schemes, with associated lists of "Critical Questions," one list for each scheme. In presumptive reasoning a proponent basically advances a claim by using a certain recognized argumentation scheme; this shifts the burden of proof to the opponent, who should then take it upon himself to rebut or criticize the argument by raising questions of the types specified for each argument scheme.

Walton's work on presumptive reasoning is valuable, first, by highlighting this notion itself and by demonstrating how widespread it is in real-life discourse, and second, by compiling and exemplifying argumentation schemes. However, as Blair has argued, both the "provenance" and the classification of Walton's schemes remain unaccounted for; "Walton's list of schemes seems to drop from out of the blue" (Blair 2001, 379). Third but not least, Walton's lists of "associated" critical questions constitute an immensely helpful resource for reasoning in several domains.

\section{Practical Reasoning}

The point where I wish to challenge Walton's theory of presumptive reasoning is where its application to practical reasoning is concerned.

Walton defines practical reasoning as "a goal-driven, knowledge-based, actionguiding species of reasoning that coordinates goals with possible alternative courses of action that are means to carry out these goals, in relation to an agent's given situation as he/she/it sees it, and concludes in a proposition that recommends a prudent course of action" (1997b, 160). Furthermore, Walton repeatedly refers to "the two basic types of practical inferences," which are "the necessary condition scheme and the sufficient condition scheme" (1996a, 11; emphases in the original). In more recent versions, though, the "sufficient condition scheme" (where the argument that an action is a sufficient to carry out a goal creates the inference that the action should be undertaken) seems to disappear, and the assumption seems to be that there is only one argumentation scheme of practical reasoning (e.g., Walton \& Godden 2005, who repeatedly refer to "the practical reasoning scheme," as if there was only one, and meaning by this the scheme where, if something is a necessary condition for realizing a goal, it creates a presumptive inference that this action should be undertaken).

While doubting parts of the basic definition, I believe to be in harmony with Walton in understanding practical reasoning as concerning action - either about whether a given action (or policy) is to be undertaken by an agent, or about what action is to be undertaken. Practical reasoning concerns decisions about actions that an agent contemplates, and which are in his or her power to undertake. 
My claim is that for practical reasoning the presumptive model is misleading. To put it in provisional terms, it is just not the case in practical argumentation that any argument for an action either creates a presumptive inference that the action it supports should be undertaken, or has something "wrong" with it. It is wrong to suggest that if not rebutted, such an argument is strong enough to immediately mandate the decision (albeit in a presumptive way); and it is just as wrong to suggest that if a pertinent critical question is raised about the argument, then it is rebutted and as it were dealt with.

An objection reminiscent of this has been made by Robert Pinto (2001, 2003). Essentially, he claims that many of the "critical questions" attached to the argumentation schemes have a purely heuristic, rather than a normative force. Hence they "cannot be used, as Walton says they can, to shift the burden of proof back to a proponent" (Pinto 2001, 112). For example, in the case of an Argument from Sign, when the critical question "Are there any other events that would more reliably account for the sign?" is raised by the respondent, then there is, according to Pinto, no burden on the proponent to show that there are no such events; instead there is a burden on the respondent to identify one.

I agree that critical questions do not automatically have the force to initiate this tennis-like back-and-forth-volleying of the burden of proof. In fact, Walton has recently modified (and mollified) his earlier conception to accommodate this insight; in regard to whether a critical question is sufficient to make the argument default, or whether the burden is on the questioner, he now finds that "this may be different for different critical questions of a scheme" (Walton, Prakken, \& Reed 2004, 86; cf. also Walton \& Godden 2005). However, my criticism is more fundamental. I reject the underlying notion introduced by the very idea of presumption: the purely "binary" view where a party either carries a burden of proof or does not, and where that burden is either incurred or shifted through presumption.

Such an implicit binarism is particularly misleading where arguments in practical reasoning are concerned. As I shall try to demonstrate with an extended example, in practical reasoning it is often legitimate, indeed necessary, to speak of degrees of strength in arguments (or "premisses"); and furthermore it is necessary to recognize that in practical reasoning the degree of strength of premisses is, in the nature of the case, often assessed subjectively and hence differently by individuals involved in the decision process.

A first reply to this criticism could be that Walton recognizes practical reasoning as a distinct domain, and that the theory of presumptive reasoning accounts for counterarguments precisely by specifying appropriate critical questions to be raised (1996a, 12).

Indeed Walton, almost alone among the argumentation theorists today who come from a philosophical background, does recognize practical argumentation as a separate domain $(1990 ; 1996 a$, p. 11-13, 176-180; 1996b; 1997b). What many overlook is the simple fact that in practical reasoning people argue about an action, 
not about a proposition or assertion. Yet Walton too, while alert to this difference, has often tended to blur it even while stating it. Commenting on a distinction between practical and "theoretical or discursive" reasoning, he states: "In the action type of critical discussion, the proposition is a practical ought-proposition that contains an imperative" (1996a, 177). This phrase is puzzling. Evidently, Walton senses that the issue in practical reasoning is not merely an "ought-proposition," and so he adds that it "contains an imperative"- thereby inventing a new hybrid. But is a proposition that "contains" an imperative still a proposition? Is an imperative not a wholly different kind of speech act? Apparently Walton, at this stage, cannot abandon the ingrained idea that reasoning, and hence also practical reasoning, is about propositions. But that for which we argue in practical reasoning is not a proposition about what we "ought" to do, nor about what is "prudent," although both these considerations (which are far from identical) may enter into the reasoning as premisses. The issue in practical reasoning is a proposal about what to do (a point I have contended, and whose implications I have tried to explore, in Kock 2003a, 2003b).

For the sake of clarity, let me state clearly that one of the distinctive features of proposals vis-à-vis propositions is that proposals are not cognitive and hence do not have truth-values. Although not everyone shares that view, I will not belabor it here, beyond an example that, in my estimate, makes it obvious. Let us take the case of a president making a proposal for his country to invade another country, say, Iraq. I do not see how what he proposes, invading Iraq, could possibly be true or false. It is an act, and acts do not have truth-values; propositions do (or some of them). However, the premisses for the proposal (e.g., that Iraq has WMD's) may have truth-values. Also, the claim that the invasion will promote democracy in the Middle East (another premiss) may have (or acquire) a truth-value. As for the value-claim that democracy in the Middle East is a highly valuable good it is a moot point whether and how such statements may have truth-values. My point is not dependent on how this question is answered. What I do claim, among other things, is that acts, and proposals to undertake acts, cannot have truth-values; that instead they have a large and open-ended range of properties, about all of which we may make propositions that may have truth-values; that about all of these properties we may make value-judgments; that these may legitimately differ across individuals; and that for all these reasons decisions about acts and proposals cannot be "inferred" from the truth of any single proposition relating to them.

Hence, even to conclude that a proposed act would be "prudent," however debatable that judgment itself might be, licences no "inference" to the act itself. We may decide to do the "prudent" thing, but on the other hand we might not, for example because considerations of ethics, duty or honor override "mere" prudence. Or again, prudent decisions may be overridden by motives such as desire for glory, thrills, or sexual pleasure. What this shows is the categorical difference between a proposition, which is the issue in theoretical/discursive reasoning, and a 
proposal, which is the issue in practical reasoning. This distinction Walton, while aware of practical reasoning as a separate domain, has repeatedly failed to formulate with any clarity.

It should be said, in all justice, that recent work by Walton on practical argumentation (2006) does much to dissipate the fog generated by earlier formulations. He now recognizes that the issue in what he calls "deliberation dialogue" is indeed a proposal, not a proposition, and that a proposal is a distinctive kind of speech act. He further presents a valuable overview of the criteria and critical questions that may be invoked in deliberation dialogue and in the appraisal of it, and he discusses other hallmarks of deliberation or practical reasoning, such as its dependence on values and the simultaneous presence in it of relevant pro and con arguments. But the fundamental notions of inference and presumption are still not questioned, nor is the implied binarism still extant in them, and the misleading and counterintuitive features of his "presumptive" account of practical reasoning which I shall discuss below remain.

\section{Walton's Inference Model}

Although Walton has moved towards clarity in accepting that deliberation/practical reasoning is about proposals, not propositions, he still assumes that what we argue for in practical reasoning follows as a conclusion or inference from a properly applied argument scheme, the way a proposition follows from its premisses by inference. In practice his revised account does not contradict formulations found in the earlier versions such as these: "In a practical inference, the conclusion is an imperative that directs the agent to a prudent course of action" (1996a, 11); "it concludes in an imperative that directs the agent to a course of action" (1990, xi). Here we have, besides the notions of "inference" and "conclusion," two additional residues from propositional logic, suggesting the binding nature of this conclusion: it is an imperative, and it directs. Walton's model of practical reasoning, and hence also of how to evaluate arguments in that domain, is still a wholehearted inference model.

Inference models of argumentation and argument evaluation (whether deductive, inductive, presumptive or otherwise) may be likened to an electrical circuit. In deductive inference, validity turns the switch on, and it stays on; if validity is absent, the switch is off and stays off. In non-monotonic inference, there is a toggle switch which can turn the inference on and off again. In the presumptive inference model the toggle switch turns a presumption of the inference on and off, while at the same time shifting the burden of proof back and forth. In all inference models, a given argument is evaluated in terms of whether it turns the inference on or not, and the switch only has two positions: on and off. This is tantamount to saying that when you accept an argument in such a model, you are bound to accept the conclusion. There is a two-way bind between argument and conclusion, even when, as in presumption, it is possible to become unbound again. 
In such a model, in order for an argument not to turn the inference (or inference presumption) on, there has to be something "wrong" with the argument, and the critical questions associated with the argument schemes are there to help identify what may be "wrong." Blair, in his critique of Walton's presumptive reasoning model, explicitly aligns presumptive inference with the deductive and inductive varieties; he refers to its "probative force" and "cogency" as if these terms were synonymous, and states that for presumptive inference, "to accept the premises and grant the validity of the inference using that scheme yet deny the plausibility of the conclusion, under the circumstances - without suggesting that any conditions of rebuttal exist - is pragmatically inconsistent" $(2001,376)$. Blair criticizes Walton for not providing rationales explaining why each argumentation scheme is cogent, but implicitly accepts that what we should expect of any argumentation is "cogency."

\section{Why the Inference Model Is Misleading}

The inference model of practical reasoning is misleading because it is not necessarily a defect in an argument used in practical reasoning that it does not authorize an inference. Walton's model, unquestioned in this respect by Blair, rests on the erroneous assumption that in practical reasoning (as in any other kind of presumptive reasoning), an argument either turns the (presumptive) inference on, or it can be rebutted. Accordingly, the critical questions which form a central part of Walton's theory are designed to rebut presumptive arguments, i.e., to throw the burden of proof back on the proponent. However, in practical reasoning an opponent of a proposal will not and should not necessarily doubt or rebut an argument proffered by the proponent; instead, he may fully acknowledge the proponent's argument, but then present a counterargument which, in his view, speaks even more strongly against the proposal than the proponent's argument speaks for it.

It might be objected here that Walton's model anticipates the existence of such counterarguments, and it does so precisely in the form of critical questions. The book version $(1996,13)$ lists the following kinds of critical questions to be asked in practical reasoning about a proposed action, A, aimed by an agent $a$, at realizing a goal, G:

Q1: Are there alternative ways (other than A) of realizing G?

Q2: Is it possible for $a$ to do A?

Q3: Does $a$ have goals other than $\mathrm{G}$ that should be taken into account?

Q4: Are there other consequences of bringing about A that should be taken into account?

The first version of this list (in 1990, 85) makes no mention of "other goals." In a later, shorter version Walton gives a slightly expanded list (1997, 610; $A$ is now the goal and $B$ the action): 
Are there alternatives to $B$ ?

Is $B$ an acceptable (or the best) alternative?

Is it possible to bring about $B$ ?

Does $B$ have bad side effects?

Are there goals other than $A$ that need to be considered?

There is no denying that these are relevant questions to raise about any proposal, and they seem to categorize possible counterarguments against it well. However, the problem is with the fundamental structure of the model, not with the questions as such.

\section{Unreasonable Implications of the Inference Model}

In the model, to adduce possible alternatives, other consequences, and other goals serves to rebut the original argument and thus turn the "practical inference" off. On this analysis, any argument for which any of the critical questions has an affirmative answer is relegated to the "off" category, along with arguments that are palpably absurd and worthless.

But any practical argument for which, e.g., one of the questions Q1-Q4 can be answered affirmatively, is certainly not by that token worthless. In practical reasoning affirmative answers to several of the questions would be the standard case. If nothing else, there will always, no matter what goal a proposal aims to promote, be "other goals" to take into account, since any person in any society will entertain multiple other wishes, purposes or values which he wants promoted. Any proposal has costs in relation to some of these other goals. For example, nearly every political action costs money, thus counteracting the "goal" of preserving our common wealth (and also counteracting all the other goals we might spend money on). So at least one of the critical questions Q1-Q4 has an affirmative answer even for arguments that most people would find highly relevant, acceptable, and strong.

Also, generally there would be no way to rebut these critical questions. Proponents would have to admit, "Yes, there are other consequences; yes, there are goals other than $\mathrm{G}$ to take into account." And there would probably be alternative actions that might serve the same goal. So every single argument for any practical proposal would find itself relegated to the "off" category. Strangely, Walton seems to think this would be the exception, e.g.: "Presumptive inferences ... are subject to withdrawal or rebuttal in exceptional cases" (1996a, xi; emphasis added). Nevertheless, what the presumption model implies is, absurdly, that any proposal to do anything for the promotion of any goal should, by the lights of state-of-theart argumentation theory, be abandoned.

Clearly, an appropriate model for practical reasoning should instead recognize it as a characteristic feature of practical reasoning that there may be legitimate, non-rebuttable arguments both for and against a proposal—arguments which would 
not necessarily contradict or refute each other. A pro-argument, A, might be perfectly true, acceptable, and relevant, and at the same time a con argument, B, might be so too; and yet they might not contradict each other at all. The contradiction would only be between the proposals they were used to support.

In other words, an argument in practical reasoning may have nothing at all wrong with it, in the sense that there is nothing to criticize or rebut, and yet it may not create any natural presumption, directive or imperative to embrace the proposal it is used to support; conversely, in order to escape the burden of proof regarding a proposal, an opponent of it does not have to criticize or rebut every argument supporting it.

But even for its unnaturalness, might not the presumptive model be defended as a handy way of stating the standard argument types in practical reasoning? No, the model is not only awkward and unrealistic when applied to practical reasoning; it as also has pernicious consequences, one of which is the following:

Because the presumptive model implies that in order for a discussant to be entitled to reject a proposal for which an argument is presented, he must rebut the argument, it follows that he must either give that proposal presumptive acceptance, or else rebut every single argument presented in its favor.

Such compulsive refusal of recognition to opposing arguments is in fact what we witness daily in public debates or interviews with politicians as participants. Politicians and other public discussants routinely behave as if recognizing any argument or any critical question from the opposite side would create a cogent inference to the opponent's proposal; hence such recognition must be avoided by any available means, including evasion, distortion or blank denial. The social harm of this practice is that the public audience gets much less of a chance to critically assess the relative strengths of the case for, respectively against, the proposal under discussion.

\section{An Alternative Model}

A theory of political and other practical argumentation which recognizes that there may be legitimate arguments on both sides of an issue would counteract this tendency. It would make clear that there need not be anything wrong or questionable about an argument in practical reasoning, but even so respondents (or voters) may be entitled to reject the proposal for which the argument is presented in support. On such a model, one may recognize the merit of a (counter-)argument without underwriting a presumptive inference to the proposal for which it argues; one would not necessarily reject the truth of the opponent's argument as such, nor its acceptability or relevance in support of the proposal, but the forced presumptive inference from recognition of the argument to acceptance of the proposal.

The presumptive model, in contrast, instantiates the same misleading binarism that inheres in other inference-based models of argumentation and argument 
evaluation. Either one accepts the argument and gets the inference to the proposal in the bargain; or, if one wants to reject the proposal, one is compelled to reject the argument, together with any other conceivable argument for the proposal as well.

Rather than institutionalizing this dilemma, argumentation theory should stop basing argument appraisal in practical reasoning on the recognition of an inference from argument to "conclusion"-_deductive, inductive, presumptive or otherwise. In practical argumentation, even legitimate arguments legitimate no inference to the proposal; instead they provide an impact of a certain strength to a decisionmaker's decision about that proposal.

The phrase "a certain amount" is crucial. A theory which is adequately to reflect in practical reasoning must conceptualize the fact that in such reasoning the strength of arguments is a matter of degrees.

In present-day argumentation theory there is a certain consensus that the criteria to be applied in argument evaluation can be formulated as acceptability, relevance, and sufficiency. This is the case in Informal Logic (see, e.g., Blair \& Johnson 1987, Blair 1992, 1995; Johnson 2000 has acceptability, truth, relevance, and sufficiency); but the same trio is also found in theory based on the pragma-dialectical framework (e.g., Henkemans 2003) and in textbook literature, (e.g., Trapp, Driscoll et al. 2005). We may speak of these three as the recognized dimensions of argument evaluation.

If argumentation theory is to conceptualize degrees of strength in arguments, which of these dimensions would it affect, and how?

Acceptability (and/or "truth") is, as it were, the epistemic dimension. As for relevance, it has to do with the argument's conceptual or qualitative correctness, its having an appropriate application to the issue at hand. For both of these dimensions, it is debatable whether and how a concept of degrees might be applicable to them. Sufficiency, however, is by its nature a quantitative, not a qualitative concept; it is about there being enough of something. In argument evaluation it says that there is enough acceptable, relevant argumentation to cross a certain threshold. But "sufficiency", like the other concepts in the triad, is a binary criterion. This is how it is used in mathematics, where, e.g., a condition is either sufficient, or it is not; there is no such thing as it being "somewhat" sufficient, or "more" sufficient than another condition. However, in practical reasoning arguments differ along the quantitative dimension not just in a binary (on-off) way, but by degrees; we have just seen the counterintuitive consequences of insisting on a purely binary conception. Yet most philosophical argumentation theory lacks theoretical tools to deal with degrees along the quantitative dimension.

\section{Degrees of Argument Strength and Subjectivity}

Arguments are sometimes referred to as having a certain weight. "Premiss weight" has been suggested as a concept in to be used in deductive logic for uncertain 
premises (e.g., Adams et al., 1975). "Fuzzy logic" (or models inspired by it) has spawned many attempts to conceptualize reasoning about concepts that "do not have crisp boundaries" (Zadeh 1965, 141).

Another precedent for using "weight" about arguments in practical reasoning is the "set of scales" metaphor, where arguments are seen as weights of varying mass, placed in the two scales. This metaphor has served the judicial system in Western countries since the Romans. The idea is that any weight in one scale is merely one element in a larger act of deliberation (a word which means "weighing on scales"). Crucial to this metaphor is the feature so characteristic of weight: it has degrees - the notion that is excluded by inference models.

The notions of gradualism and of the aggregate totality of arguments are well embodied by the "scales" image. But another implication of that image is less appropriate. Weight/mass, as a purely physical parameter, suggests that there is an objective, physically determinable mass to any single argument-and hence a possibility of determining, with precision and objectivity, which scale outweighs the other.

Trudy Govier makes just this point in a note on the idea of "weighing" reasons in the chapter on "Conductive Arguments and Counterconsiderations" in her widely used text, A Practical Study of Argument: "No implication that we can mathematically measure or judge the relevance and comparative strength of various reasons or counterconsiderations is intended at this point. The metaphor of 'weighing' could be deemed misleading; however, it does not seem possible to eliminate it save by substituting another metaphor" (2004, 415, note 5).

Precisely the wish to make well-defined, intersubjectively valid inferences and calculations even with fuzzy premisses drives the attempts to use "weight" and related physical concepts in theories inspired by Fuzzy Logic and related conceptions. But just as a binary quantitative argument evaluation cannot be upheld in practical reasoning, intersubjectivity too cannot be fully upheld.

The need to recognize degrees of premiss strength is only the first necessary step. In addition, we must recognize that individuals may evaluate a given premiss differently along the quantitative dimension. The lack of intersubjectivity in this respect is the reason why "weight" is a questionable metaphor. Instead, we might simply refer to the quantitative dimension of arguments in practical reasoning as "strength."

Are we driven, then, to the conclusion that the appraisal of argument strength in practical reasoning inherently involves a subjective element? My answer is yes.

Govier, however, presents a "method for appraising conductive arguments" that some might see as aiming at objective appraisal of conductive argumentsdefined, following Wellman (1971), as cases where there are several separately relevant premises both on the pro and the con side, which is precisely the category where practical reasoning belongs. The method involves determining the acceptability and relevance of all premises that may be adduced on both sides and then judging 
which side outweighs the other. Cautiously, Govier neither claims nor denies that this (rather commonsensical) procedure will yield "objective" appraisal. But she does say this: "To reflect on what the pros and cons are, and how you would evaluate them or 'weigh up' the reasons requires good judgment, which you have to supply for yourself" $(2004,404)$. An earlier version of the text had formulations like this: "Answers, however, especially for issues as profound as that of euthanasia, will emerge from individual judgment about the significance of the various factors" (1992, 311).

All in all, the denial of "mathematical" weighing, the use of the second person pronoun, and the reference to "individual" judgment which "you have to supply for yourself" make it clear that Govier does not see her method as yielding objective or intersubjective appraisal, but rather as involving a subjective element, at least in the "weighing" of the factors-although she seems reluctant to say so. This reluctance might have to do with the fact that she does not set off practical reasoning as a separate domain within conductive argument, and/or with her background as a philosopher. Other texts by writers with a rhetorical background are less hesitant to acknowledge this subjective element explicitly, as in this statement: "In many ethical judgments, you and your audience might agree on certain values, but not necessarily rank them in the same way. ... most of the time weighting will be the crucial issue for your audience. People are quite likely to agree about the relevance of a set of criteria, but they often disagree about which particular one are most important in a given situation" (Fahnestock and Secor, 2004, p. 249).

I concur. To reiterate the two claims I make about argument "strength" in practical reasoning, they are: 1) We must conceptualize argument strength as a non-binary, that is, gradualistic ("scalar") notion. 2) We must conceptualize the fact that the strength assigned to arguments in practical reasoning may legitimately differ from one individual to another.

I will support these claims, which together also provide my main reasons for questioning Walton's presumptive model of practical reasoning, by discussing an authentic, paradigmatic example.

\section{An Example of Practical Reasoning: the Euro Debate}

A practical political issue in many European countries in the "nineties was the adoption of a common currency, the Euro. In most countries this issue was decided by Parliament; some countries had referendums (Denmark, 2000; result: rejection. Sweden, 2003; result: rejection). Other countries are currently deliberating the issue.

In these debates, several macroeconomic arguments have been proffered, mainly predictions of likely consequences of either adoption or rejection of the Euro. Some arguments have turned on microeconomics and simple convenience: e.g., it is easier to travel between countries if one does not have to change one's cash. Arguments of yet another nature have had to do with the political implications, in 
a broader sense, of Europe (or most of it) going together on one single currency. Other arguments invoke feelings of national identity, or the symbolic significance of a national currency. As is well known, many people in Germany were reluctant to abandon the Deutschmark, but most German skeptics have now apparently acquiesced. On the other hand, there is a continuing wish among Britons to retain Sterling for reasons that have to do, at least in part, with national identity, and these feelings are strong enough to make the Government move with extreme caution on the issue.

We have here a paradigm case of an issue in practical reasoning. It illustrates a number of significant facts, stated above, about practical reasoning in general.

First, let us consider the argument that if a country joins the Euro, its citizens will not have to change their money nearly as often when traveling between European countries. There is no doubt that this is a true ("acceptable") argument: all else equal, international travel will undeniably be easier with the Euro. Also, this argument is undoubtedly relevant; greater ease of international travel is an irrefutable advantage of adopting the Euro. However, it would be hard to find many who feel that this premiss alone-we may call it the convenience argument—is "sufficient" to trigger adoption of the Euro as an inference. On the other hand, it is also clear that there is nothing "wrong" or defective at all about the convenience argument. Even if one does not see it as reason enough to join the Euro, it is undeniably an argument of some strength. Notice that this strength, such as it is, cannot be rebutted or annulled; it counts (although most people would probably agree that it does not have "a lot of" strength).

So, clearly, in practical reasoning arguments may have a certain degree of strength which may not, however, be considered sufficient to trigger what Walton calls a directive inference, but which still counts.

Moreover, given that an argument has some degree of strength, it will not necessarily have the same degree of strength for everyone. This formulation is of course of a rather intuitive nature; what "the same" means in this context is so far unclear. We might imagine an empirical definition, by which individuals would have to mark the perceived strength of the argument on a 1-7 Likert scale; a fair prediction is that not all marks would hit the same point on the scale, although most marks would probably cluster at the lower end.

Again, we might think of two different types of people, e.g., a person living in a rural inland area who rarely travels abroad, and a businessperson who does so regularly. It is entirely plausible that to the latter person the convenience argument would have more strength than it would to the former. We might say that to both these people the convenience of a common currency would be an advantage of some value, but that to one of them this value is greater than it is to the other. Furthermore, we should recognize that this difference between the two people regarding the respective strength they assign to the convenience argument is completely "legitimate." It matters less to the first person than it does to the second. 
This undeniable circumstance shows that in practical argumentation at least, there is such a thing as argument strength which legitimately varies from one person to the next.

It might be objected to this example that it is somehow "wrong" for a given voter, in deciding whether to vote for the Euro, to think merely of his or her own subjective convenience. Arguably what both our individuals ought to do would be to consider what is best for the country, since they are presumably both going to be involved in a collective decision for the country as a whole.

Let us accept this premiss for the sake of the argument. Still, regarding the relative strengths of the arguments that we have enumerated, we would find legitimate individual differences which could not be delegitimized or explained away by theory. The convenience argument has not been the only one to play a part in the Euro debates. (If it had been the only relevant one-but only in that unnatural case-then we might have had a presumptive inference in favor of joining the Euro.) On any such issue there are, as a matter of course, countless other considerations: the macro- and microeconomic ones, political goals, and considerations relating to national identity, symbolic significance, etc. The simultaneous existence of all these explains why no single argument on such an issue can be sufficient to trigger a directive inference, even though a number of these considerations might all be acceptable, relevant and endowed with some strength.

What concerns us just now is that to some people a given consideration, e.g., Sterling's "national-symbolic" value, may have more relative strength than it does to others. As a matter of fact, it appears that in Britain national-symbolic arguments have sufficient strength for many people to override arguments relating to convenience or economics. If we agree that this divergent assignment of argument strength across individuals is an empirical fact, then the question is whether argumentation theory should recognize it as legitimate-or whether such a recognition should be condemned as relativistic. Of course it is legitimate, and a fact argumentation theory should describe and account for, not try to legislate out of existence. For example, to some Britons the status of the Sterling as a symbol of national identity has sufficient strength as an argument to determine their stand against the Euro. To other Britons, the "national identity" argument may also be a strong anti-Euro argument, but they may not perceive it as quite strong enough to override the economic or political arguments they believe speak for the Euro. To still another group of Britons, the "national identity" argument is perhaps of utterly negligible strength; to them, it may even have what we might call negative strength, in the sense that traditional feelings of British national identity are so unappealing to them that they would be more than willing to give up any tokens of such feelings the sooner the better. 


\section{What the Example Demonstrates}

We may define "degrees of strength" in some absolute sense or in a relative sense (as describing how strong a given argument is perceived to be by a given person in relation to other arguments). What the example of the "national identity" argument demonstrates is, again, that in practical reasoning an argument may legitimately have different degrees of strength to different people; and it would demonstrate this no matter which absolute or relative definition of strength we might devise.

Our example has also shown a fundamental yet curiously under-theorized circumstance: in practical reasoning arguers appeal to a multiplicity of goals to which those who are to decide are committed. Walton is aware of this when he describes practical reasoning as "a goal-driven, knowledge-based, action-guiding species of reasoning that coordinates goals with possible alternative courses of action that are mans to carry out these goals" $(1997,608)$. This formulation captures much of the complexity of practical reasoning. It is precisely true that there are always several goals which must be coordinated; and that is the primary reason why practical reasoning is unfit to be modeled as presumptive. Unfortunately, however, Walton forgets this insight when he repeatedly refers to "the local inference used in practical reasoning," in which " $A$ is the goal," and, since " $B$ is necessary to bring about $A$, Therefore, it is required to bring about $B$ " $(1997,608)$. Such a conception, where there is only one goal and one argument scheme in view, and where anything that is necessary to bring that goal about is then "required," is inadvertently suggestive of a closed mindset utterly alien to all that Walton stands for.

Instead of speaking about "goals," a terminology which perhaps encourages narrowing "one-goal-at-a-time" conception of practical reasoning, we might speak about values. Any "goal" implies that ones assigns a value to a certain state of affairs that ones wishes to promote. In practical deliberation, several values are involved for each participating individual. A proposal may be seen, by each individual, as promoting some of his or her values and at the same time as counteracting others. It then becomes a question, for that individual, of how strongly the decision is seen as promoting or counteracting the values involved. Further, the decision depends on the strength of the individual's commitment to each of the pertinent values. Whether we want to define the "strength" of these values, for each individual, in absolute terms or in relative terms, the fact remains that not all individuals, not even all individuals in a circumscribed cultural group (such as "all Britons"), can legitimately be expected to hold identical sets of values, arranged in the same relative order-or "hierarchy," to use Perelman's and Olbrechts-Tyteca's term $(1969,80-84)$. So, when facing a practical proposal, such as adopting the Euro, each individual who is to decide and, possibly, participate in the debate, will, in principle, consider the arguments proffered in it from the vantage point of his or her own hierarchical set of values. 


\section{The Charge of Relativism}

A claim such as this runs the risk of being branded by some argumentation theorists as "relativism." The charge of relativism against other theories has been made repeatedly in writings by the Pragma-Dialectical school (most recently in van Eemeren \& Grootendorst 2004, 130, with reference to Perelman \& OlbrechtsTyteca, 1969). A similar criticism has recently been made, in very sweeping fashion, by Boger (2005).

The attack on relativism, but also much of the theory that is under attack for alleged relativism, is based on the tacit but faulty assumption that this scholarly issue is about audience relativity ("relativism") in all argumentation and in all compartments of argument evaluation. In other words, the mistake on all sides is a failure to distinguish between those domains and types of argumentation where audience relativity is inherently present, and those where it is not. Proponents of audience relativity tend to write as if their claims have reference to all argumentation; their critics make the same mistake. Consequently, the scholarly discussion becomes a rather pointless quarrel where one party is perceived as saying that all evaluation criteria in argumentation are audience-relative, and the other party counters this perceived claim by saying, indignantly, that their opponents are perniciously relativistic and that all evaluation criteria should certainly be audience-independent. What I argue is not that all evaluation criteria are audience-relative, but that some are, more specifically those pertaining to the degree of relative strength of valuebased arguments in practical reasoning.

Thus, if argument strength, in value-based practical reasoning, legitimately varies from one person to the next, it does not deserve to be called "relativism" or the like, if this term implies that argumentation theory ought not to recognize such a thing. The convenience of not having to change currency when traveling will matter in different degrees to people who deliberate the Euro issue. A theory which refuses to conceptualize facts such as this commits a grave error of omission; a proper theory should describe them and find proper places for them.

Calling such a theory "relativistic" does not make the facts it describes less true or more avoidable. What alternative description could a "non-relativistic" argumentation offer? Would it venture to assess objectively precisely how strong the various arguments in, e.g., the Euro debate, are? Will argumentation scholars tell voters just how much strength they ought to assign to the convenience argument, to the "national identity" argument, and to the economic and political arguments, respectively? Or would argumentation theorists, to evade recognition of this alleged relativism, fall back on the time-worn denial strategy of postulating that all arguments, in practical reasoning as in logic, are either valid or invalid? While many argumentation theorists, including Douglas Walton, have abandoned deductive validity as the sole criterion of argument evaluation, and while the new concepts and categorizations which they have suggested have indeed deepened our insight 
into the workings of real-life argument, still when it comes to argument appraisal they have largely remained transfixed by the linear and binary mode of thinking characteristic of deductive logic. The few exceptions, such as Wellman's notion of "conduction" (1971), have received too little attention. Theorists have been afraid of opening the door to gradualism in the appraisal of argument strength, perhaps because they see that they will then have no way of avoiding what they abhor as "relativism." Thus, newer concepts to substitute traditional "validity" have not managed to (or even sought to) escape binarism; that is equally true whether the criterion suggested is "sufficiency," or, as in Walton's presumptive reasoning, correct use of argumentation schemes.

True enough, there are many aspects of everyday argumentation on which argumentation scholars can and should pronounce evaluative assessments in binary terms. In the public sphere we may every day hear moves which are unequivocally fallacious or dishonest and deserve exposure. Yet, as Walton has repeatedly shown, there are just as many points where argumentation scholars have been overzealous to pronounce generalized, categorical judgment. Walton has added countless welcome nuances to the appraisal of real-life argumentation. However, where practical reasoning is concerned - and the Euro debate is just one instance of that -his presumptive model fails to capture some of the central features. Because practical reasoning deals with actions and with the multiple values which provide warrants for them, it works in a way that argumentation scholars should study rather than be uncomfortable with: there are degrees of argument strength; the appraisal of degrees of argument strength may be inherently subjective; and this is legitimately so.

\section{References}

Adams, E.W., \& Levine, H.P.(1975). On the uncertainties transmitted from premises to conclusions in deductive inferences. Synthese, 30, 429-460.

Blair, J.A. (1992). Premissary relevance. Argumentation, 6, 203-217.

Blair, J.A. (1995). Informal logic and reasoning in evaluation. New Directions for Program Evaluation 68, 71-80.

Blair, J.A. (2001). Walton's argumentation schemes for presumptive reasoning: A critique and development. Argumentation, 15, 365-379.

Blair, J.A., \& Johnson, R. (1987). Argumentation as dialectical. Argumentation, 1, 41-56.

Boger, G. (2005). Subordinating truth—is acceptability acceptable? Argumentation, 19, 187-238.

van Eemeren, F. V., \& Grootendorst, R. (2004). A systematic theory of argumentation: The pragma-dialectical approach. Cambridge: Cambridge University Press.

Fahnestock, J., \& Secor, M. (2004). A rhetoric of argument. (Third edition.) Boston: McGraw-Hill.

Govier. T. (1992). A practical study of argument. (Third edition.). Belmont, CA. : Wadsworth. 
Govier. T. (2004). A practical study of argument. (Sixth edition.). Belmont, CA. : Wadsworth.

Henkemans, A. F. S. (2003). Complex argumentation in a critical discussion. Argumentation, 17, 405-419.

Holmstrom-Hintikka, G., \& Toumela, R. (Eds.). Contemporary action theory. Vol. 1 (pp. 159-175). Dordrecht: Kluwer.

Kock, C. (2003a). Gravity too is relative: On the logic of deliberative debate. In van Eemeren, F. H., Blair, J. A., Willard, C. A., \& Henkemans, A. F. S. (Eds.). Proceedings of the fifth conference of the international society for the study of argumentation (pp. 627-632). Amsterdam: Sic Sat.

Kock, C. (2003b). Multidimensionality and non-deductiveness in deliberative argumentation". In van Eemeren, F. Anyone who has a view: Theoretical contributions to the study of argumentation (pp. 157-171). Dordrecht: Kluwer.

Perelman, C. L., \& Olbrechts-Tyteca, L. (1969). The new rhetoric: A treatise on argumentation. Notre Dame: University of Notre Dame Press.

Pinto, R.C. (2001). Argument, inference and dialectic: Collected papers on informal logic (Argumentation Library). Dordrecht: Kluwer.

Pinto, R.C. (2003). Commentary on C. Reed \& D. Walton's “Argumentation Schemes in Argument-as-Process and Argument-as-Product”. In J.A. Blair, D. Farr, H.V. Hansen, R.H. Johnson and C.W. Tindale (Eds.), Informal logic at 25: Proceedings of the Windsor conference. Windsor, ON: OSSA.

Reiter, R. (1980). A logic for default reasoning. Artificial Intelligence, 13, 81-132.

Rescher, N. (1976). Plausible reasoning: An introduction to the theory and practice of plausibilistic inference. Assen-Amsterdam: Van Gorcum.

Trapp, R., Driscoll, W., \& Zompetti, J.P. (2005). Discovering the world through debate: A practical guide to educational debate for debaters, coaches and judges. New York: Central European University Press.

Walton, D. N. (1990). Practical reasoning: Goal-driven, knowledge-based, actionguiding argumentation. Savage, Maryland: Rowman and Littlefield.

Walton, D. N. (1991). Rules for plausible reasoning. Informal Logic, 14, 33-51.

Walton, D. N. (1993). The speech act of presumption. Pragmatics and Cognition, 1, 125-148.

Walton, D. N. (1996a). Argumentation schemes for presumptive reasoning. Mahwah, N.J.: Lawrence Erlbaum Associates.

Walton, D. N. (1996b). Practical reasoning and the structure of fear appeal arguments. Philosophy and Rhetoric, 29, 301-313.

Walton, D. N. (1997a). How can logic best be applied to arguments? Logic Journal of the IGPL, 5, 603-614.

Walton, D. N. (1997b). Actions and inconsistency: The closure problem of practical reasoning. In Holmstrom-Hintikka, G., \& Tuomela, R. (Eds.). Contemporary action theory, Vol. 1 (pp. 159-175). Dordrecht: Kluwer.

Walton, D. N. (2001). Abductive, presumptive and plausible arguments. Informal Logic, 21, 141-169. 


\section{8}

Walton, D. N., Prakken, H., \& Reed, C. (2004). Argumentation schemes and burden of proof. In Grasso, F., Reed, C., \& Carenini, G. (Eds.). Working notes of the 4th international workshop on computational models of natural argument (CMNA2004) (pp. 81-86). ECAI: Valencia, 2004.

Walton, D.N., \& Godden, D. (2005). The nature and status of critical questions in argumentation schemes. In Hitchcock, $D$. (Ed.). The uses of argument: Proceedings of a conference at McMaster University, 18-21 May 2005 (pp. 476-484). Hamilton, Ontario: OSSA.

Walton, D. N. (2006). How to make and defend a proposal in a deliberation dialogue. Artificial Intelligence and Law. DOI 10.1007/s10506-006-9025-x. 63 pp.

Wellman, C. (1971). Challenge and response: Justification in ethics. Carbondale and Edwardsville: Southern Illinois University Press.

Zadeh, L.A. (1965). Fuzzy sets. Information and control, 8, 338-353.

Christian Kock Department of Media, Cognition and Communication University of Copenhagen

Njalsgade 80

2300 Copenhagen $S$ Denmark

kock@hum.ku.dk 